\title{
Produção de energia elétrica através da biomassa em sistema de gaseificação concorrente e grupo gerador com capacidade de $50 \mathrm{kVA}$.
}

\author{
Production of electricity through biomass gasification system \\ downdraft and generator group with a capacity of $50 \mathrm{kVA}$.
}

\author{
Fabrízio L. Figueiredo ${ }^{1}$; Fernando Fernandes²; Aron L. Petrucci³ ${ }^{3}$ Roberto F. Filho ${ }^{4}$; \\ Marcelo Marsura 5 .
}

\section{Resumo}

Este trabalho apresenta os resultados de testes realizados com um motor de combustão interna MWM adaptado a ciclo Otto, acoplado a um gerador de eletricidade com capacidade de $50 \mathrm{kVA}$, alimentado exclusivamente com gás de síntese proveniente de um gaseificador de biomassa concorrente utilizando lenha de eucalipto. Também são apresentadas as características e eficiência do conjunto gerador, com o objetivo de avaliar a viabilidade de se aplicar o sistema em localidades distantes, onde há biomassa disponível e o sistema de transmissão de energia elétrica convencional é dificultado pela distância. $\mathrm{O}$ gás de síntese gerado apresentou composição média de $16,9 \%$ de $\mathrm{H}_{2}, 20 \%$ de $\mathrm{CO}, 10,9 \%$ de $\mathrm{CO}_{2}, 2 \%$ de $\mathrm{CH}_{4}$ e $50,1 \%$ de $\mathrm{N}_{2}$. O desempenho do conjunto gerador foi monitorado aplicando-se cargas de 0 , $7,13,20,1$ e 26,4 kW, ao grupo gerador, mantendo a tensão média de $222 \mathrm{~V}$ e correntes de $0,18,5,33$, 51, 84 e 67 A.

Palavras-chave: Gaseificação, gás de síntese, geração de eletricidade.

\begin{abstract}
This paper presents the results of tests performed with an internal combustion engine adapted to MWM Otto cycle, coupled to an electricity generator with a capacity of $50 \mathrm{kVA}$, fed exclusively with synthesis gas from a biomass gasifier downdraft, using wood eucalyptus. Also featured are the characteristics and efficiency of the generator set, in order to assess the feasibility of applying the system in remote locations, where biomass is available and the system of conventional electric power transmission is hampered by distance. The synthesis gas generated showed the average composition of $16,9 \% \mathrm{H}_{2}, 20 \%$ $\mathrm{CO}, 10,9 \% \mathrm{CO}_{2}, \mathrm{CH}_{4}, 2 \%$ and $50,1 \% \mathrm{~N}_{2}$. The performance of the span was monitored by applying loads of $0,7,13,20,1$ and $26,4 \mathrm{~kW}$, the generator, keeping the average voltage of $222 \mathrm{~V}$ and currents of 0 , $18,5,33,51,84$ and $67 \mathrm{~A}$.
\end{abstract}

Key words: Generator. Synthesis gas. Gasifier income test.

\footnotetext{
${ }^{1}$ Aluno de mestrado Engenharia de Edificações e Saneamento (CTU), Universidade Estadual de Londrina; fabrizio.figueiredo@ yahoo.com.br.

${ }^{2}$ Doutor em tratamentos de resíduos pelo Instituto Nacional Politécnico de Toulouse e professor associado (CTU - UEL); fernando@uel.br.

${ }^{3}$ Doutor em Eng. Civil pela Universidade de São Paulo. Professor associado (CTU - UEL); aron@uel.br.

${ }^{4}$ Consultor Sênior - Petrobras; furini@petrobras.com.br.

${ }^{5}$ Engenheiro Eletricista, ERBR - Energias Renováveis Brasil Ltda.; marcelo@erbr.com.br.
} 


\section{Introdução}

As limitações de recursos naturais de petróleo, bem como os efeitos já indiscutivelmente comprovados do aquecimento global colocam em questão a necessidade de meios alternativos de geração de energia sem que o meio ambiente seja agredido.

Entre as energias renováveis, uma das mais importantes fontes no futuro em curto prazo é a biomassa (BRIDGWATER, 1995). Esta é definida como toda substância orgânica renovável de origem animal e vegetal, que se deve seu caráter energético à conversão da energia solar.

Zurich, (2008), descreve a biomassa como um termo diverso, mas em se tratando de gaseificação, refere-se há tecidos de plantas ou mais especificamente a madeira.

A grande vantagem da biomassa como fonte renovável de energia, está relacionada com a mitigação das emissões do $\mathrm{CO}_{2}$. Neste sentido, é dado que todo o $\mathrm{CO}_{2}$ emitido na utilização energética da biomassa tenha sido previamente fixado no crescimento da matéria vegetal. Como principais desvantagens estão sua baixa densidade e seu considerável conteúdo de umidade que influem nos custos associados ao seu transporte para o seu aproveitamento energético.

A gaseificação é um processo de conversão térmica no qual se produz, a partir de biomassa, um gás combustível genericamente chamado de gás de síntese. No processo foi usado o ar, como agente de gaseificação, podendo ser usado também $\mathrm{O}_{2}$, e vapor de água (BELGIORNO, 2003), (HIGMAN, VAN DER BURGT, 2003). É descrita como sendo um processo de conversão térmica da matéria orgânica em combustível, usando um agente de gaseificação. Para Kinto (2001), a gaseificação se trata da desvolatização e a conversão da biomassa, em uma atmosfera de vapor ou ar (ou ambos), para a produção de um gás de médio ou baixo poder calorífico. O processo ocorre numa atmosfera pobre em oxigênio, onde o substrato orgânico passa pelas fases de secagem, pirólise, oxidação e redução. Gaseificador é o equipamento onde ocorre o processo.

Os gaseificadores são classificados de acordo com a direção do movimento relativo da biomassa e do agente de gaseificação em contracorrente (updraft), concorrente (downdraft), fluxo cruzado, leito fluidizado e leito arrastado. Em Lahti, Finlândia existe em operação um de leito fluidizado circulante, operando desde 1998; e, na Universidade de Zaragoza, Espanha, na década de 90 foi desenvolvido experimento num gaseificador de leito fixo concorrente para madeira.

Para Cortez, Lora e Gómez (2008), os gaseificadores concorrentes são os mais indicados na produção de gás para alimentação de motores de combustão interna já que produtos da pirólise, entre eles, o alcatrão, será reduzido na zona de oxidação, devido às altas temperaturas nesta região. O gaseificador utilizado no projeto piloto foi um concorrente de duplo estágio de gaseificação, a fim de se reduzir ao máximo a quantidade de alcatrão e particulados.

Para compor um grupo gerador de $50 \mathrm{kVA}$, com motor ciclo Otto é necessário um motor com potência maior que os disponíveis no mercado nacional. A empresa ER-BR energias renováveis informa que para suprir essa carência, motores ciclo Diesel podem ser convertidos para funcionar à ciclo Otto, abastecido somente com gás de síntese. Deste modo, adaptado um motor ciclo Diesel com as especificações necessárias, transformando-o em ciclo Otto.

O objetivo deste trabalho é avaliar o desempenho de uma planta piloto do sistema de gaseificação em leito fixo concorrente de duplo estágio; utilizando lenha de eucalipto como substrato na geração do gás combustível, para a alimentação do motor MWM convertido para ciclo Otto e de 50 $\mathrm{kVA}$, tendo como produto final a geração de energia elétrica. 


\section{Materiais e Métodos}

\section{Gaseificador}

O sistema piloto de gaseificação usado neste trabalho é um sistema de leito fixo, concorrente, com dois estágios de gaseificação, onde na parte superior é feita a alimentação, em seguida se encontra a zona de secagem, pirólise, oxidação e redução. Segundo Reddy, Farell e Stanford (1995), denomina-se assim pelo fato de que a operação continua, na medida em que o combustível é alimentado e as cinzas retiradas; concorrente, devido a fato o combustível ser fornecido pela parte superior em tanto que o ar movimenta se em sentido descendente, podendo ser alimentado lateralmente ou pela parte superior do reator. A principal vantagem deste tipo de reatores é a pouca quantidade de alcatrão no gás energético produzido, devido ao craqueamento do mesmo ao passar pelas regiões de alta temperatura do processo (zona de combustão) e de duplo estágio devido ao fato do agente gaseificador (ar nesse caso) ser injetado em duas regiões do gaseificador, o que cria duas zonas de alta temperatura, através dos quais os voláteis, da região de pirólise, devem passar, provocando o craqueamento térmico do alcatrão propiciando a geração de um gás mais limpo. O ar é injetado no gaseificador, por meio de um soprador de 3405 rpm e regulado por uma válvula de acordo com a variação da pressão em centímetros de coluna d'água,variando de 2,6 a 3,1 cm $\mathrm{H}_{2} \mathrm{O}$. Essa variação influencia diretamente na quantidade de gás produzido e consequentemente maior consumo de biomassa e uma ligeira e breve diminuição das temperaturas. Para o teor de alcatrão, valores menores que $500 \mathrm{mg} / \mathrm{Nm}^{3}$ são aceitáveis, sendo preferíveis valores menores que $100 \mathrm{mg} / \mathrm{Nm}^{3}$ (QUAAK; KNOEF; STASSEN, 1999). A Figura 1 apresenta um esquema de gaseificador em reator de leito fixo concorrente. Após a etapa de gaseificação é feito um pré-tratamento do gás, e em seguida enviado ao motor.

Figura 1 - Gaseificador de leito fixo concorrente de duplo estágio de gaseificação.

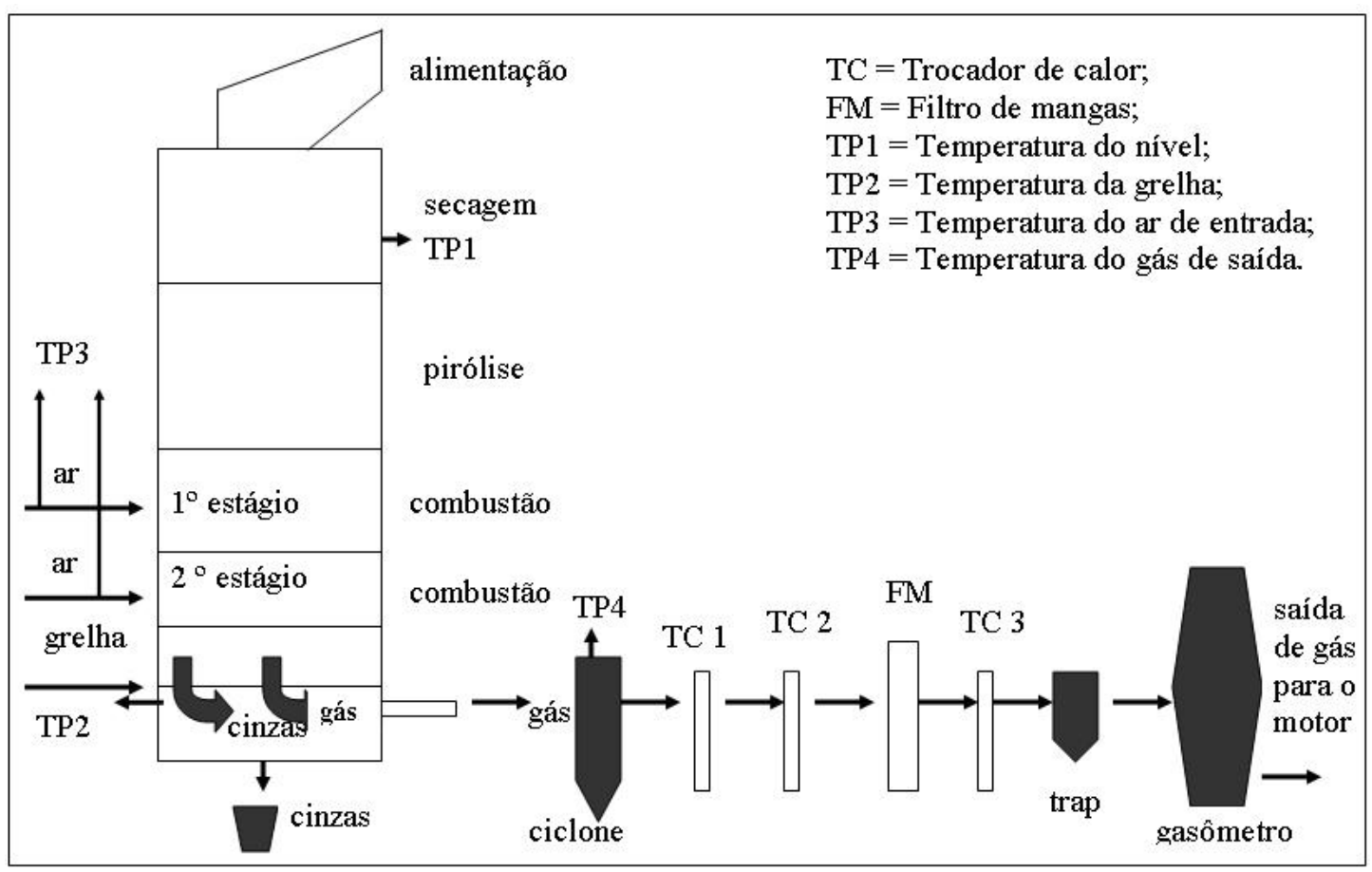

Fonte: O autor. 


\section{Biomassa}

A biomassa utilizada no processo de gaseificação do teste foi madeira de eucalipto cortado em pedaços cilíndricos, com diâmetro de $80 \mathrm{~mm}$ e altura de $90 \mathrm{~mm}$ aproximadamente, e umidade média de $16,42 \%$, de um total de cinco pedaços retirados aleatoriamente da pilha e medida com um Higrômetro Digisystem DL 2000. São descritas na Tabela 1, as características da madeira pela análise imediata, antes de ser feita a sua combustão e na análise elementar, após sua combustão.

Tabela 1 - Características da lenha de eucalipto utilizado.

\begin{tabular}{llc}
\hline \multicolumn{3}{l}{ Substrato } \\
\hline Poder calorífico & PCI & $16,14 \mathrm{MJ} / \mathrm{Kg}$ \\
& PCS & $18,96 \mathrm{MJ} / \mathrm{Kg}$ \\
\hline Análise Imediata & Voláteis & $77,5 \%$ \\
& Carbono Fixo & $16,7 \%$ \\
& Cinzas & $0,41 \%$ \\
\hline Análise Elementar & Hidrogênio & $6,4 \%$ \\
& Oxigênio & $41,8 \%$ \\
& Nitrogênio & $0,4 \%$ \\
& Enxofre & $* *$ N.I. \\
\hline
\end{tabular}

Fonte: Barrichelo e Brito (1978) - adaptado.

Após o fim da operação do gaseificador foram coletadas as cinzas e o material particulado do ciclone para fazer análise da quantidade da massa gerada de resíduo, por meio de pesagem dos mesmos.

\section{Grupo Gerador}

O grupo gerador é composto por um motor MWM adaptado a ciclo Otto, já que não se encontra no mercado nacional motores de grande porte da categoria Otto, mas existem motores ciclo Diesel de grande porte. As principais modificações realizadas foram: a retirada de alimentação diesel, colocação de velas, controle de velocidade, sistema de equalização de entrada de gás. O controle da entrada da mistura ar combustível é feita pelo corpo borboleta de acordo com a necessidade imposta pela variação de carga no motor. A Tabela 2 resume as principais características grupo gerador.

Tabela 2 - Principais características do grupo gerador.

\begin{tabular}{lc}
\hline Motor & MWM D 229-4 \\
\hline $\begin{array}{l}\text { Aspiração } \\
\text { Disposição / cilindros / } \\
\text { válvulas }\end{array}$ & Linha / 4 / 8 válvulas \\
Cilindrada total & 3.92 Litros \\
Diâmetro X curso & 102 x 120 mm \\
Taxa de compressão & $11: 1$ \\
Sistema de ignição & ER-BR \\
Misturador ar/combustível & Mixer 50 \\
\hline Gerador & Kohlbach Kcel \\
\hline Rotação (rpm) & $1800 \pm 10 \%$ \\
Potência Prime* & 48 kVA $(38 \mathrm{~kW})$ \\
Potência Stand By** & $50 \mathrm{kVA}(45 \mathrm{~kW})$ \\
Tensão (V) & $127 / 220-220 / 380$ \\
\hline
\end{tabular}

*funcionamento contínuo; **funcionamento temporário. Fonte: ER-BR, energias renováveis, 2010.

O responsável pela geração da eletricidade é o gerador KOHLBACH KCEL acoplado ao motor. Trata-se de um síncrono brushless devido ao fato de que neste tipo de gerador o regulador se adequa á velocidade do rotor, possui controle eletrônico do tipo isócrono com controle por sensor eletromagnético e proteção contra sub e sobre velocidade. Assim sendo, o valor da velocidade de referência $\left(\mathrm{W}_{\text {ref }}\right)$ varia com a potência ativa de carga. Com limitações na capacidade da geração de energia de acordo com sua aplicação e regime de funcionamento ele gera no máximo 50 kVA (45 
$\mathrm{kW}$ ) quando aplicáveis para fornecimento de energia elétrica (com carga variável) no caso de falha de uma rede pública, ou $48 \mathrm{kVA}(38 \mathrm{~kW})$ aplicáveis para fornecimento contínuo de energia elétrica quando o motor é alimentado com diesel, e tensões de saída de $127-220 \mathrm{~V}$ ou $220-380 \mathrm{~V}$ de acordo com o fabricante. Essas limitações são para preservar o desgaste prematuro do equipamento. Testes efetuados com o mesmo grupo gerador alimentado com GNV resultaram numa carga máxima de $38 \mathrm{~kW}$ (FIGUEIREDO et al., 2011).

\section{Operação e monitoramento do sistema piloto}

O gaseificador entrou em operação com uma carga de $0,3 \mathrm{~m}^{3}$ de carvão vegetal mais $0,7 \mathrm{~m}^{3}$ de madeira de eucalipto, com umidade média de $16,42 \%$. O peso médio da madeira em cada recarga é de $30 \mathrm{~kg}$ e volume de $0,1 \mathrm{~m}^{3}$, incluindo os vazios. A velocidade da grelha foi fixada em aproximadamente 1 volta por hora. O monitoramento da composição do gás foi feito desde o início de operação, em pontos específicos como chama piloto, antes do filtro de mangas, antes do gasômetro, escapamento do motor e depois do gasômetro, de maior relevância.

A análise da quantidade de oxigênio $\left(\mathrm{O}_{2}-\right.$ comburente e não combustível) no gás de síntese foi feito pelo equipamento Servomex 570A, e detector paramagnético. Para determinação da quantidade de monóxido de carbono ( $\mathrm{CO}$ - levemente inflamável), metano $\left(\mathrm{CH}_{4}\right.$ - combustível), nitrogênio $\left(\mathrm{N}_{2}-\right.$ inerte) e dióxido de carbono $\left(\mathrm{CO}_{2}\right.$ - liberado da queima de combustíveis) foi utilizado cromatógrafo gasoso SRI, modelo $8610 \mathrm{C}$ e para o hidrogênio $\left(\mathrm{H}_{2}\right.$ - combustível) cromatógrafo gasoso marca Varian modelo CG 3400 por meio de detecção por condutividade térmica.

Foram também, monitoradas as temperaturas do gás de saída, da temperatura do nível, que informa o momento de recarga, e a temperatura do ar de entrada, que é pré-aquecido trocando calor com o gás gerado. As temperaturas foram registradas com termopares Makil.
Inicialmente o motor foi ligado com GLP (gás liquefeito de petróleo), que garante uma fácil ignição e um perfeito funcionamento do sistema. Para o motor foi monitorado a temperatura da água do radiador, a temperatura do óleo lubrificante, a pressão do óleo e a rotação (que varia de acordo com a carga aplicada), pelos próprios instrumentos de medição do motor, e a temperatura de escape, com termômetro Impac modelo IP-550. Para o gerador foi monitorado a potência ativa $(\mathrm{kW})$ desenvolvida e a tensão (V), ambos pelo multímetro com função de osciloscópio Fluke 43 Energy Analyser, e a corrente (A) com um multímetro Minipa modelo 620.

A energia elétrica produzida pelo grupo gerador foi dissipada por um banco de cargas puramente resistivas divididas em 6 potências totalizando 32,4 kW. São elas: 5,3; 5,3; 5,3; 3,5; 6 e 7 kW.

O volume de condensado retirado do Trap foi medido com um Béquer.

\section{Resultados e discussões}

\section{Desempenho geral do gaseificador}

O consumo médio de substrato durante o teste foi de 49,6 kg/hora, com um total de $300 \mathrm{~kg}$ no ciclo. Observou-se que como não se variou muito a quantidade de gás produzida, as recargas se mantiveram constantes sendo executada uma a cada 50 minutos, aproximadamente.

Verificou-se que após 1 hora e 40 minutos de funcionamento a variação da temperatura do nível se estabilizou, em decorrência da estabilização térmica geral do sistema. Entretanto, ainda observaram-se pequenas oscilações, devido ao fato que conforme a biomassa é consumida, vai se diminuindo a camada isolante e aumentando a temperatura, informando o momento de uma nova recarga.

A temperatura do ar de entrada se elevou a 57 ${ }^{\circ} \mathrm{C}$ em 100 minutos, se mantendo praticamente estável por mais 130 minutos. Após o motor ligado a temperatura se elevou alcançando picos de 125 
${ }^{\circ} \mathrm{C}$ em 250 minutos e $173{ }^{\circ} \mathrm{C}$ em 300 minutos, devido à diminuição do volume de gás no interior do gaseificador.

Foi observado que a temperatura do gás de saída, coletado após o gasômetro teve um aumento brusco de $335{ }^{\circ} \mathrm{C}$ em 80 minutos, subindo mais lentamente até os $430{ }^{\circ} \mathrm{C}$ em 230 minutos, tendendo a se estabilizar nesta faixa de temperatura com o motor ligado, sofrendo pequenas oscilações, devido à quantidade de carga aplicada ao motor, como pode ser observado na Figura 2.

Figura 2 - Variação da temperatura do gás de saída, de acordo com tempo de funcionamento do gaseificador.

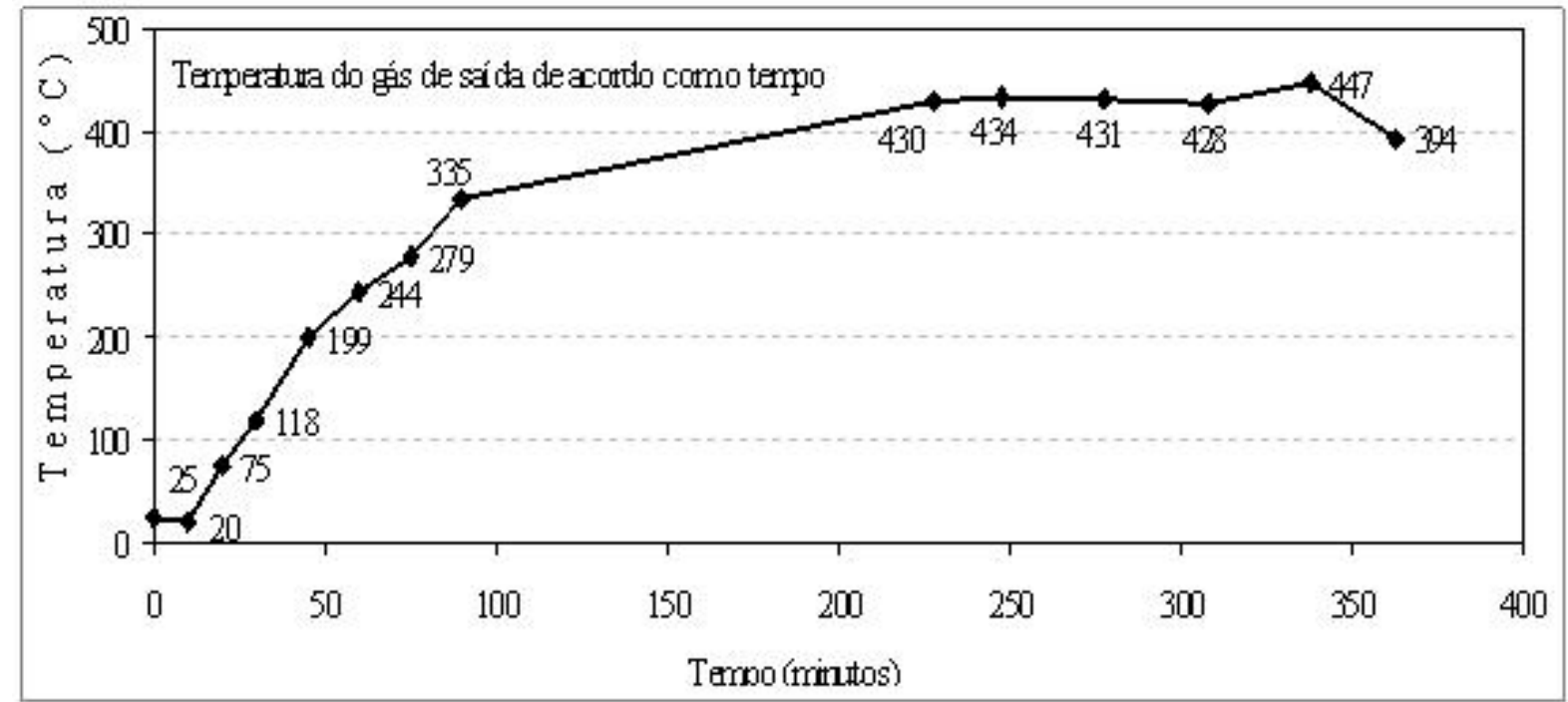

Fonte: O autor.

Os pontos de coleta, bem como a composição do gás analisado em cada um desses pontos são apresentados na Tabela 3. Os valores são médios de cinco leituras para cada local. O maior número de leituras foi após o gasômetro, por não sofrer mais intervenções à partir daí.

Tabela 3 - Composição do gás de síntese coletado em 4 diferentes pontos.

\begin{tabular}{|l|c|c|c|c|c|c|}
\hline \multicolumn{1}{|c|}{ Gás } & $\begin{array}{c}\text { Hidrogênio } \\
\mathbf{( \% )}\end{array}$ & $\begin{array}{c}\text { Oxigênio } \\
\mathbf{( \% )}\end{array}$ & $\begin{array}{c}\text { Nitrogênio } \\
\mathbf{( \% )}\end{array}$ & $\begin{array}{c}\text { Monóxido de } \\
\text { carbono (\%) }\end{array}$ & $\begin{array}{c}\text { Dióxido de } \\
\text { carbono (\%) }\end{array}$ & Metano (\%) \\
\hline $\begin{array}{l}\text { Chama } \\
\text { piloto }\end{array}$ & 14,5 & 0,25 & 0,6 & 21,0 & 11,2 & 2,5 \\
\hline $\begin{array}{l}\text { Antes do } \\
\text { filtro }\end{array}$ & 12,1 & 5,8 & 54,3 & 15,9 & 10,4 & 1,5 \\
\hline $\begin{array}{l}\text { Antes do } \\
\text { gasômetro }\end{array}$ & 12,3 & 5,45 & 59 & 13,95 & 7,9 & 1,45 \\
\hline $\begin{array}{l}\text { Depois do } \\
\text { gasômetro }\end{array}$ & 16,9 & 0,1 & 50,1 & 20,0 & 10,9 & 2,0 \\
\hline
\end{tabular}

Fonte: O autor. 
Todas as medições foram efetuadas num intervalo de tempo de 85 minutos. Observa-se pela Figura 3 que a composição do hidrogênio se manteve praticamente estável, variando entre 16,3 e $17,7 \%$. Para o metano composição se manteve entre 1,8 e $2,3 \%$, muito abaixo que o GNV que é em torno de $70 \%$.
O nitrogênio está presente em grande concentração, entre 47,3 e $51,1 \%$, sendo desnecessária a sua presença. $\mathrm{O}$ monóxido de carbono atua como comburente, se mantendo estável na média de $20 \%$ e o dióxido de carbono na média de $10,7 \%$, responsável $97 \%$ das emissões totais de gases de efeito estufa.

Figura 3 - Variação da composição do gás de síntese ao longo do tempo, coletado após o gasômetro.

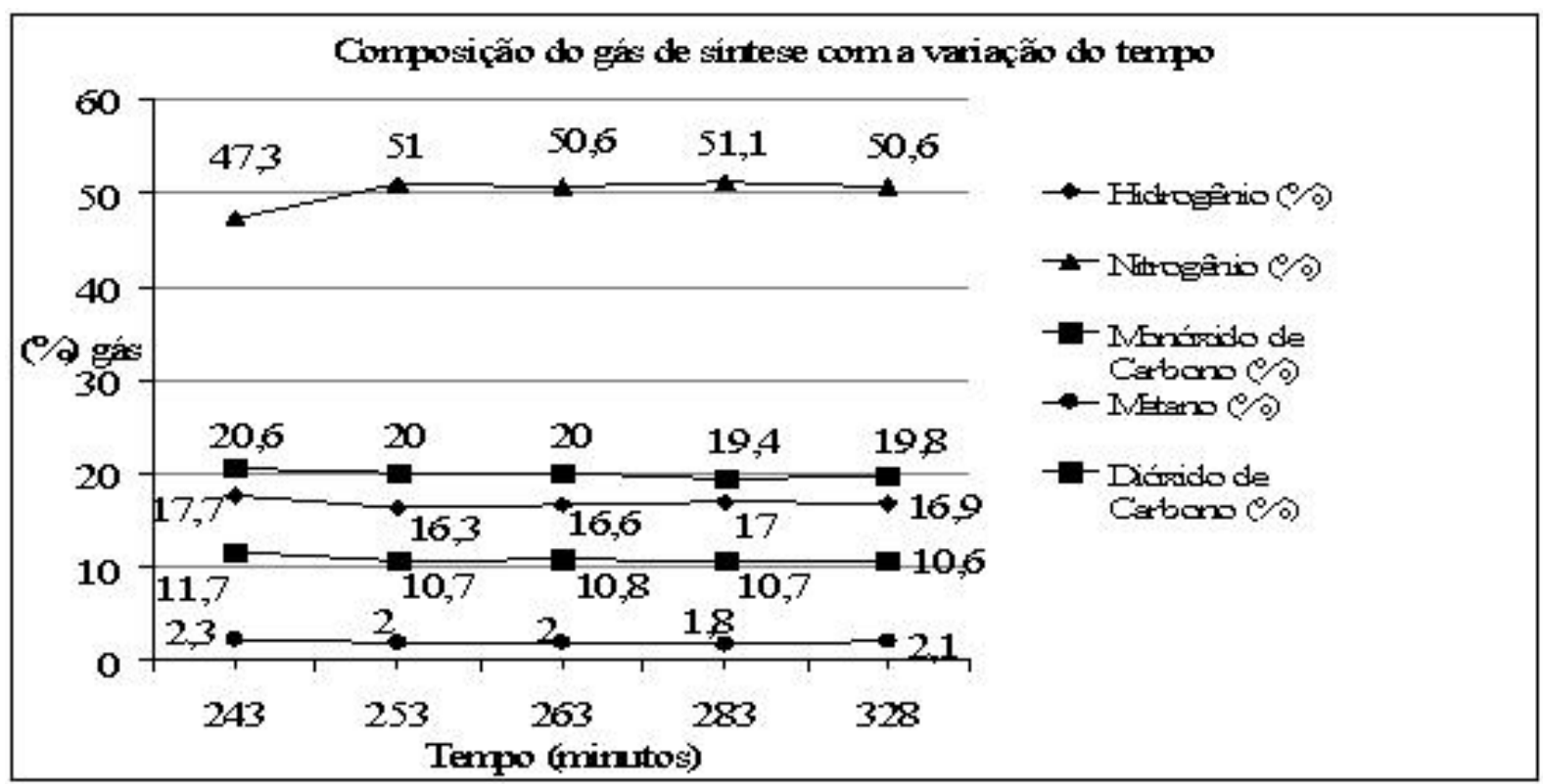

De modo geral, a composição do gás não sofreu variações bruscas, mantendo-se estável.

Fonte: $\mathrm{O}$ autor.

A medida da composição do gás também foi realizada uma única vez na saída do escapamento do motor ficando da seguinte forma: $\mathrm{H}_{2}, 0,1 \%$; $\mathrm{O}_{2}, 0,2 \% ; \mathrm{N}_{2}, 79,0 \% ; \mathrm{CO}, 1,8 \% ; \mathrm{CO}_{2}, 18,9 \%$ e $\mathrm{CH}_{4}, 0,1 \%$. Os resultados demonstram que o gás é queimado no motor, mas uma pequena quantidade não, devido ao fato do motor não ter sido construído especificamente para ser abastecido com gás de síntese.

Após o ciclo foram recolhidas as cinzas retiradas pela grelha ficando em 264,61g, material particulado coletado pelo ciclone em $145,02 \mathrm{~g}$ e o condensado do gás retido pelo trap com $400 \mathrm{ml}$.

\section{Desempenho do grupo gerador}

A Tabela 4 apresenta as medidas realizadas em 5 diferentes níveis de carga, sendo eles: $0(0 \%), 7 \mathrm{~kW}$, $13 \mathrm{~kW}, 20,1 \mathrm{~kW}$ e $26,4 \mathrm{~kW}(100 \%)$. Além da carga máxima suprida pelo grupo verificou-se para cada intervalo a tensão $(\mathrm{V})$, a corrente $(\mathrm{A})$, a temperatura da água do sistema de arrefecimento $\left({ }^{\circ} \mathrm{C}\right)$, a temperatura do óleo lubrificante $\left({ }^{\circ} \mathrm{C}\right)$, a pressão do óleo (bar), a temperatura do escapamento $\left({ }^{\circ} \mathrm{C}\right)$ e rotação do motor (rpm). 
Tabela 4 - Resultados do monitoramento do grupo gerador.

\begin{tabular}{lccccc}
\hline Carga (kW) & $\mathbf{0}$ & $\mathbf{7}$ & $\mathbf{1 3}$ & $\mathbf{2 0 , 1}$ & $\mathbf{2 6 , 4}$ \\
\hline Tensão (V) & 222 & 223 & 223 & 223 & 223 \\
Corrente (A) & 0 & 18,5 & 33 & 51,84 & 67 \\
Temperatura água $\left({ }^{\circ} \mathrm{C}\right)$ & 82 & 82 & 82 & 83 & 84 \\
Temperatura óleo $\left({ }^{\circ} \mathrm{C}\right)$ & 89 & 91 & 93 & 94 & 95 \\
Pressão de óleo (bar) & 5,3 & 6,5 & 6,4 & 6,5 & 6,9 \\
Temperatura escape $\left({ }^{\circ} \mathrm{C}\right)$ & 560 & 590 & 602 & 611 & 625 \\
Rotação (rpm) & 1800 & 1762,22 & 1710 & 1657,8 & 1636,2 \\
\hline
\end{tabular}

Fonte: $\mathrm{O}$ autor.

Observa-se também pela Figura 4 que a corrente aumenta linearmente à medida que a carga é aplicada, sem distorções e sem aumento brusco, mesmo com a carga máxima suportada de $26,4 \mathrm{~kW}$, de potência ativa. Se a carga aplicada fosse maior, aí sim ocorreriam distorções, com aumento da corrente desproporcional e diminuição da tensão, além de alterar outras condições de funcionamento como, por exemplo, a diminuição da rotação, causando distorções na qualidade de energia e causar danos ao grupo. A tensão se manteve entre 222 e $223 \mathrm{~V}$.

Observa-se também que quanto mais carga se aplicada, menor é a rotação do motor, permanecendo inversamente proporcional a relação carga aplicada/ rotação do motor, dentro dos limites estabelecidos pelo fabricante de $10 \%$.

Figura 4 - Variação da corrente em função da carga aplicada ao grupo.

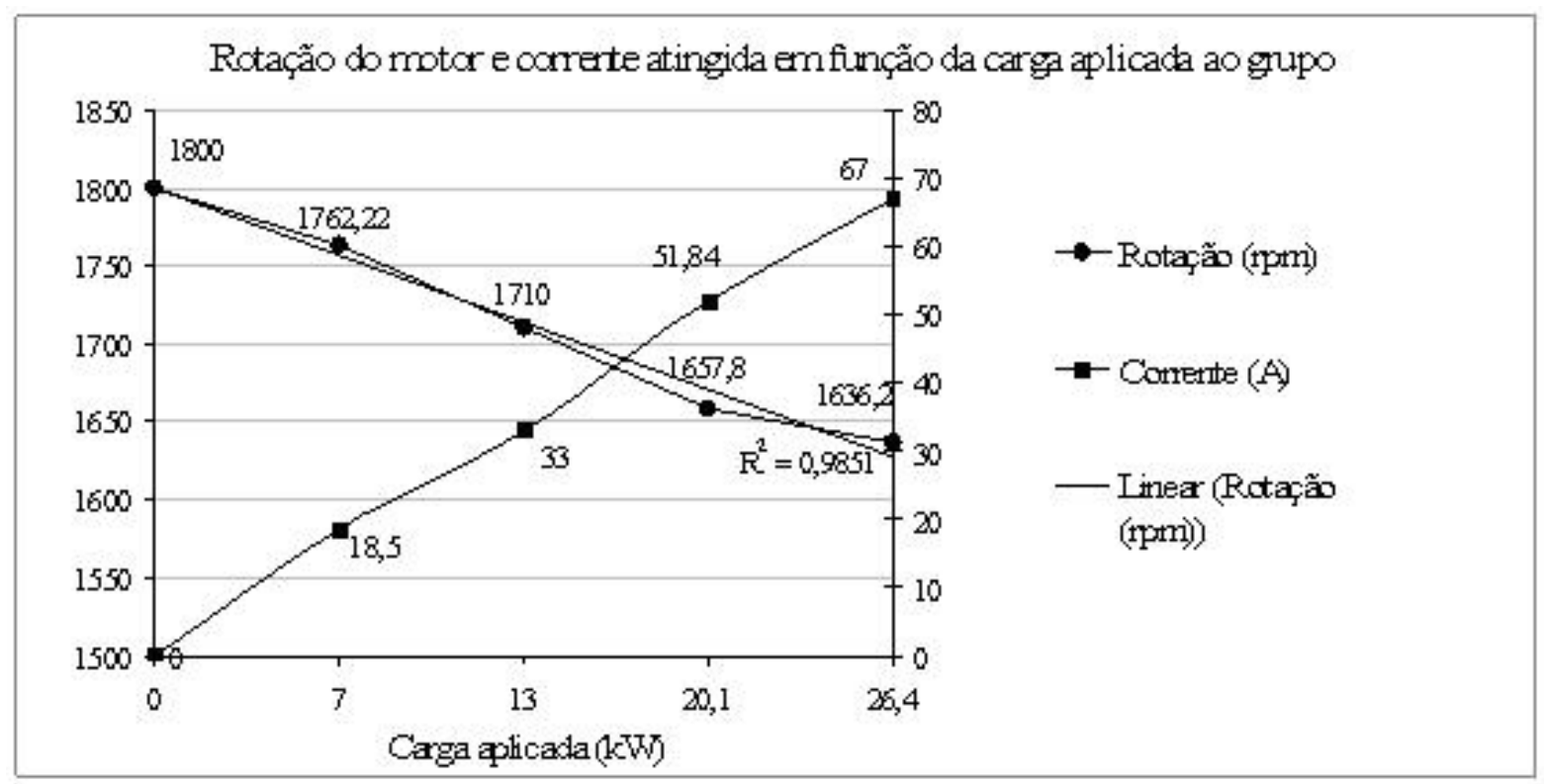

Fonte: $\mathrm{O}$ autor. 
Para cada intervalo de carga aplicada foi registrada também a diminuição da rotação do motor. A Figura 4 também apresenta a variação de rotação do motor conforme a carga aplicada. Observase que com a carga máxima a rotação é de 1636,2 rpm, dentro dos patamares recomendados pelo fabricante. Com a aplicação de uma carga superior, a rotação tende a cair mais, não conseguindo suprir a carga, aumentando-se muito a corrente e causando distorções e queda na tensão.

\section{Conclusões}

- A quantidade média de substrato consumido foi de $49,6 \mathrm{~kg} / \mathrm{h}$, com teor de umidade médio de $16,42 \%$;

- No gás de síntese produzido, foram detectadas a média dos gases, em porcentagem de $16,9 \%$ de $\mathrm{H}_{2}$, $0,1 \%$ de $\mathrm{O}_{2}, 50,1 \%$ de $\mathrm{N}_{2}, 20,0 \%$ de $\mathrm{CO}, 10,9 \%$ de $\mathrm{CO}_{2}$ e $2,0 \%$ de $\mathrm{CH}_{4}$; as concentrações de $\mathrm{H}_{2}$ foram detectadas na composição do gás após o gasômetro. Considerando que o ar injetado no gaseificador foi o ambiente, esta concentração é considerada alta, por se tratar de um gás combustível; já para o nitrogênio a quantidade também é alta, em comparação com o gás natural veicular (GNV) que é de no máximo $3 \%$, porém, por ser inerte, não contribui positivamente com o poder calorífico do gás de síntese;

- O gaseificador produziu a quantidade de gás suficiente para suprir a demanda do grupo gerador em potência máxima de $26,4 \mathrm{~kW}$;

- Com o motor em funcionamento as temperaturas internas do gaseificador tendem a ficar maiores, devido ao consumo do gás aumentar, diminuindo o volume deste no interior do gaseificador;

- Quantidades de 0,1 \% de hidrogênio e metano foram detectadas no escapamento do motor, caracterizando uma queima não perfeita do combustível, o que é considerável, pois o sistema não foi desenvolvido exclusivamente para funcionar com gás de síntese e sim com biogás;
- O grupo gerador apresentou bom desempenho utilizando o gás de síntese, sem distorções na qualidade da energia gerada para potência máxima desenvolvida de $26,4 \mathrm{~kW}$ de potência ativa;

- A tensão se manteve estável, dentro dos padrões fixados pela Companhia Paranaense de Energia (COMPANHIA PARANAENSE DE ENERGIA, 1999), variando somente entre 222 e $223 \mathrm{~V}$, sendo permitida a variação entre 221 a $229 \mathrm{~V}$.

\section{Agradecimentos}

- Universidade Estadual de Londrina (UEL);

- ER-BR - Energias Renováveis;

- Petrobrás;

- GET - Global Energy and Telecom;

- IPT - Instituto de Pesquisa e Tecnologia;

\section{Referências}

BARRICHELO, L. E. G.; BRITO, J. O. Características do eucalipto como combustível: análise química imediata da madeira e da casca. IPEF, Piracicaba, n. 16, p. 63-70, 1978.

BELGIORNO, V.; FEO, G. D.; NAPOLI, R. M.A. Energy from gasification of solid wastes. Waste Management, Oxford, v. 23, p. 1-15, 2003.

BRIDGWATER, A. V. The technical and economic feasibility of biomass gasification for power generation. Fuel, London, v. 74, p. 631-653, maio 1995.

COMPANHIA PARANAENSE DE ENERGIA. NTC 901100: Fornecimento em tensão secundária de distribuição. Curitiba: CNMD, 1999.

CORTEZ, L. A. B.; LORA, E. E. S.; GÓMEZ, E. O. Biomassa para energia. Campinas: Unicamp, 2008.

ER-BR energias renováveis. Londrina - PR. http://www. erbr.com.br.

FIGUEIREDO, F. L. Avaliação de uma unidade autônoma de produção de energia elétrica composta por sistema de gaseificação concorrente e grupo gerador com capacidade de 50 kVA.2012. Dissertação de Mestrado Universidade Estadual de Londrina: UEL. 
HIGMAN, C.; VAN DER BURGT, M. Gasification. Oxford: Gulf Professional Publishing, 2003.

KINTO, O. T. Produção local de energia através da gaseificação da biomassa para geração de energia elétrica no Médio Paranapanema. Escola Politécnica da Universidade de São Paulo, 2001.

QUAAK, P.; KNOEF, H.; STASSEN, H. Energy from biomass: a review of combustion and gasification technologies. Washington, D.C, USA: 1999. (Word Bank Technical Paper, n. 422, Energy Series).

REDDY, S.; FARELL, A.; STANFORD, T. Evaluation and implementation of control strategies for moving-bed coal gasifiers using MGAS. The Chemical Engineering Journal, Lausanne, v. 59, n. 2, p. 133-141, 1995.

ZURICH, E. Electricity from wood through the combination of gasification and solid oxide fuel cells Systems analysis and Proof-of-concept. Stuttgart: Universität Stuttgart/Federal Republic of Germany, 2008.

Recebido em 18 Outubro 2011-Received on October 18, 2011. Aceito em 21 Março, 2012 - Accepted on March 21, 2012. 